\title{
Short Forms and Unalloyed Genre
}

\author{
Matthew Sangster
}

As SOON AS THE WORDS 'Once upon a time' pass your lips, the nature of your story is made clear. In four words you have established that you are telling a fairy tale. You are, of course, under no obligation to keep telling such a tale, but you have invoked a powerful set of thematic and stylistic conventions which you can follow or subvert. One of these is that the story you are telling will be short, for once a fairy tale grows too long, it ceases to be primarily a fairy tale and becomes other things as well. It is in short forms that genres find their purest expressions, and it is through playing with the resonant conventions of modes and genres that much of the best writing in short forms achieves its impact. For example, the six word story attributed to Ernest Hemingway - 'For sale: baby shoes, never worn.' - depends on the sharp turn from advertisement to the complexity of implied elegy or occluded tragedy for its powerful effect. ${ }^{1}$

In novels, such form-based kicks are generally diluted by the mass of words surrounding them. The novel is a baggy form, presenting a maximalist invocation of a world, or at least a thematically repetitious, self-reinforcing accumulation of text. Most novels feel obliged to profusely pile up modes and ideas in order to justify their being called novels; only a few hardy experimenters display the admirable concision of Augusto Monterroso, who wrote the work hailed by Umberto Eco as the shortest novel ever written translated, this reads in full: 'When he awoke, the dinosaur was still there.' 
Monterroso's story gestures out - to the dream, to the previous appearance of the dinosaur, to the waking presence. It awakens and leaves open possibilities. By contrast, many more conventional novels display a kind of anxiety about being complete-in-themselves, possibly resulting from the enormous amount of work that goes into their creation. To justify readers' time there is a sense that novels must encompass capacious, consistent worlds, or be definitive, somehow regarding a tighter focus. In novels, genres and closed discourses proliferate. Their pleasures are rarely unalloyed.

This is not to imply that novels are bad and shorter forms good, merely that some stories can be told most purely and powerfully in a brief time. The best short fiction uses the established conventions of language, genre and form to distill something bright and clear and singular. While most novels are hybrids, short stories can give you conceptions, forms and genres, neat. Brevity empowers the most powerful of H.P. Lovecraft's cosmic horrors, in which a protagonist is only briefly sketched before their world is ripped out from under them to reveal a brutalising presence, temporally or spatially vast, which casts human life as tiny and trivial. Short forms best accommodate Jorge Luis Borges' beautiful constructions, which adroitly and brilliantly explore a wondrous idea and then, having reached a natural conclusion, come to a graceful stop. They allow Anton Chekhov to dissect and make paramount the little ways that people succeed or fail in their attempts to be caring humans. They let Arthur Conan Doyle set up a problem for Watson to delineate and Holmes to solve without loose words diluting the impact and centrality of the mystery. In all these writers brevity is a great strength, the confines of the short story empowering. The short story can accommodate a risky starkness, a bold focus on a problem or aspect or contradiction. Where the novelist must continue to invent, the short story writer can simply stop.

Another way of putting this would be to say that short fiction is prepared to lie in more bare-faced fashion than novels. In short works the reader is closer to the outside. A short piece has less space to accrete a realistic world, or a fantastic world with a fully fleshed-out set of rules. Rather than attempting to swallow the reader, then, as novels often do, short stories invite their readers to fill in the gaps, induce them to immediate involvement. The fairy tale's 'Once upon a time', rather than demanding that readers lose themselves, invites them to collude in the storytelling process, challenges them to accept or deny the story as a story. Short fiction is unselfconscious about conventions, foregrounding and playing with them. It is generous, graspable and tractable, ripe for reconfiguration - think of August Derleth building a mythos out of Lovecraft, or Angela Carter's fairytale blends, or Chekhov's later plays, which can seem like a set of his short stories playing out contrapuntally. By having the courage to be unalloyed tales, short stories call for close attention, promoting better, more active readings alive to both the bright hope and the nagging cynicism evoked by the queasy words 'And they all lived happily ever after.'

\section{Royal Holloway College, University of London}




\section{Notes}

${ }^{1}$ Possibly apocryphal anecdote, cited in numerous print and online sources. Whatever the truth of it, it's a pretty good story.

${ }^{2}$ In Spanish,'Cuando despertó, el dinosaurio todavía estaba allí.' Augusto Monterroso, 'The Dinosaur ('El Dinosaurio') in Complete Works and Other Stories, tr. Edith Grossman (Austin: University of Texas Press, 1995), p. 42. 